Univerza v Ljubljani

\title{
NAGLASNA ZNAMENJA V BOHORIČEVIH ZIMSKIH URICAH 1584
}

11 O naglasnih znamenjih v Bohoričevi slovnici 1584 je podrobneje pisal že pater Stanislav Škrabec, ${ }^{0} \mathrm{za}$ njim pa 1.1968 Jakob Rigler $^{1}$ in 1971 Rudolf Kolarič. ${ }^{2}$

1.0 Škrabec je iz Bohoričeve slovnice navedel 81 enot s krativcem, nato pa iz Dalmatinovega prevoda Biblije še 48 in iz Megiserjevega slovarja 159240 . Škrabčev komentar k tem izpisom: "/S/vojega pravila /o rabi akuta in brevisa/ se drži Bohorič primeroma jako natanko in stanovitno. /.../ Popolnoma dosleden Bohorič seveda ni, piše precej pogosto samo $e$ ali $a$ namesto $\dot{e}$ ali $a$, večkrat tudi $i$ : sin sna, pijanic, razločik, gladik, požrešin. Zraven kokèr pozna tudi kakòr. /.../ To in ono v njegovi pisavi vtegne biti tiskovna pomota, gravis namesto akuta in nasprotno, npr. prešèrn nam. prešérèn." (Škrabec zglede navaja v navadnem črkopisu svojega časa.) Dalje: "Tudi v Dalmatinovi bibliji stoji za $\mathrm{b}$ pogostoma $a ̀$ ali $\grave{e}$, še večkrat seveda sam $a$ ali $e$, tudi $i . "$ In: "Celo Megiser v svojem Dictionarium quatuor linguarum 1592 rabi v mnogih primerih è in včasih à za b." Škrabec je opozoril še na upoštevanje tega v Hrenovih Evangelijih in listih in tudi v Schönlebnovi 2. izdaji le-teh.

1.1 Rigler je podrobneje obravnaval samo "/o/značevanje jata z $e^{\prime \prime}$ (str. 201), takole: "Medtem ko Dalmatinu é označuje predvsem $\check{e}$, pa je pri Bohoriču razmerje drugačno. Pri njem ni razlike med pogostnostjo zapisov z é glede na to, ali gre za refleks $\breve{e}$ ali ne, ampak označuje é le dolgi e. To vidimo /.../ tudi iz primerov kot: Diléshni 48 , Korén 49 , Léd 50, Magnét 50, Ne frézhen 51, Ognénik 5, Ohtér 51, (O)zhéta 51, Pleménit itd., kjer ima $e ́$ za etimološki ali nazalni $e$, na drugi strani pa iz pogostnih $e$ za $\check{e} / . f^{\prime \prime}$

1.2 Pri Kolariču ${ }^{2}$ pa o naši tematiki najdemo naslednje ugotovitve: Str. 38: Bohorič enozložnicam ne zapisuje naglasa, razen "če se izgovarjajo hitreje; tedaj jih zaznamuje s krativcem: pèr, kàr, tàr. Torej imajo neonaglašene enozložnice naglas na dolžini". In k temu Kolarič prav tam: "Osebni zaimek jaz, narečno jèst, ima gotovo kratki padajoči naglas. Če ga Bohorič daje za zgled med dolgoizgovorjenimi enozložnimi besedami, to pomeni, da ga je občutil kot dolgega in ga zato označil z ostrivcem. Že iz tega edinega zgleda lahko sklenemo, da $\mathrm{v}$ njegovi domači govorici (Dobrova-Rajhenburg-Krško) ni bilo izrazitega kolikostnega nasprotja več. Piše namreč: npr. medén (ega) kot Medèn, niga 50, Nòshizhèk (za nožícek ali nóžiček) 51, Túp 54 (za tóp tọ:pa -o)." Dalje Kolarič našteva še naslednje zglede: Pogléd 52, Zerkoú 54 (tudi Zerkov, Zerkva), Zuntér 54, Pi hà̀ 58, Semlà -lè 58, lè /dejansko z é/, Turén -rna 54, shèna 58, Lètú 58 "Annus" 62, Sviné, -éta 63, bódél 128 ("samoglasniške kakovosti se niso razločevale"),

${ }^{0}$ Naša fonetika v prozi in poeziji, Cvetje z vertov sv. Frančiška 30 (1913), 5. zvezek, str. b-č.

${ }^{1}$ Začetki slovenskega knjižnega jezika, 1968, pasus Bohoričev jezik na str. 200-203.

2 R. Kolarič: Die Sprache in Adam Bohoričs Arcticae horulae, v: Adam Bohorič: Arcticae horulae, die erste Grammatik der slowenischen Sprache. - Wittenberg 1584. II. Teil: Untersuchungen. RT München 1971, str. 29-82 v poglavju Quantität, Intonation, Wortakzent, n. d. str. 38-40. 
Je Dotáknem 129, Schlahtén (-an)" itd. ${ }^{3}$ "Z ostrivcem Bohorič zaznamuje tudi resnično dolge samoglasnike, npr. Bokál 48, Diléshni 48, Duhá 48, Enák 48, Kovázh 49, Kroták 50, Lagák 50, Léd 50, Listár 50 /tako tudi Pleteršnik, SSKJ pa samo lístarica/, Méh, á 50, Mehák 50 /dejansko Mekák/ 50, Oblák 51, Piániz 51, Vál na vodi 54, Arja nashelési 55, Perú, á 62 (kot senộ-â), Nebéjku itd." Naglasom /kot/ pitjé, pozhutenjé /.../ njegove domače govorice je težko pritrditi; severnejšim štajerskim narečjem so /pa/ dobro znani." In: "Iz Bohoričevega naglašanja, ki svojim lastnim pravilom ne ustreza, lahko le sklepamo, da so se kratki naglašeni samoglasniki že podaljšali in da niso več obstajala nobena prava kolikostna nasprotja pri naglašenih zlogih.

Isto bi se lahko reklo za intonacijska nasprotja na podlagi njegovih zapisov. $\mathrm{Ni}$ jih več bilo: intonacija je bila samo še padajoča na naglašenih zlogih (dolgih ali največ poldolgih). Danes so južno Bohorja samo dolgi naglašeni zlogi; kratki so le nenaglašeni zlogi."4

Pri dvozložnih besedah je po Bohoriču (str. 266 moje izdaje AHS) naglašen prvi zlog (delam, pijhem). "Sicer je treba zadnji zlog naglasno zaznamovati, npr. vajlám valeo, Predám vendo."

Trozložnice pa imajo naglašen predpredzadnji zlog, npr. delamo, delate, delajo. Drugačna mesta naglasa "je treba zaznamovati z ostrivcem, npr. velímo, velíte". Kolaričev komentar: "Tudi tega pravila se je Bohorič držal zelo redko."

Po 4. pravilu bi bilo treba naglas vedno zaznamovati, če je treba samoglasnik izgovoriti "raptim" (= hitro, s silo).

Končno pri Bohoriču zvemo še, da naglasno mesto lahko ločuje pomen: vàjlam /.../ volvo, volvis, volvit : vajlám, álh á, tj. valeo, es, et (veljam) vel in precio Jum.

1.3 Medtem ko k Riglerju nimamo pripomb, kolikor obravnava pisanje črke $\dot{e}$, je k od Kolariča povedanemu mogoče povedati marsikaj kritičnega. To bomo storili tako, da bomo po vrsti obravnavali vse $\mathrm{z}$ naglasniki zaznamovane enote $\mathrm{v}$ Bohoričevi slovnici, to pa po seznamu sestavka Jožeta Stabeja Slowenisch-lateinisches-deutsches (zum Teil) Wörterbuch der Grammatik von Adam Bohorič, v AB: AH EGSS, slovar na str. 147-203. Stabej je zelo zanesljiv jezikoslovni delavec, škoda je le, da pomožnega glago-

\footnotetext{
${ }^{3}$ Oglejmo si te stvari podrobneje po posameznih besedah:

leden, niga: Prav bi bilo dniga, kakor Bohorič v večini tudi res zapisuje drugo obliko besede $\mathrm{z}$ neobstojnim samoglasnikom, npr. Hiter, triga ali Hlapèz, pza itn.

Nòshizhèk: pač [nôžičək], medtem ko je mogoče naglašen tudi le polglasnik, kakor imamo npr. fantèk, ki ima celo akutsko podstavo.

Túp, a: Za obliko tup govori v SSKJ oblika na srednji spol: stil. topó. S. I. Ožegov 1964: tupój -ája -óe, kratka oblika túp tupá túpo, túpi. Mostec: túp -a-u

Zerkou tudi Zerkov in Zerkva. Kolaričevega Zerkoú Stabej ne potrjuje.

Zuntér: To je pogrešek za Zuntèr.

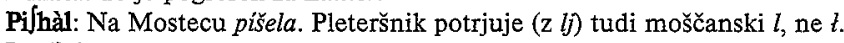

Poglèd: Pri Bohoriču in Stabeju Pogléd. Na Mostecu res ozki naglašeni e.

Turén: Verjetno tiskovna napaka z é nam. $z$ è.

porozhéna shèna: Oba onaglašena $e$-ja sta široka in dolga.

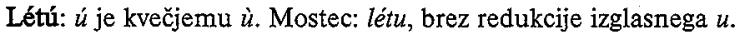

Sviné, éta: Ta tip se $z$ Mosteca potrjuje s prasè (knjižno prasệ).

Podobno pri oblikah za deležnik na $-l$.

${ }^{4}$ Moščanski govor ima za akutirane zloge in zložni $r$ dolžine, kračine iste barve samoglasnikov pa kažejo na nekdanji cirkumfleks na dolžini. Daljšanja kračin ne pozna.
} 
la ni izpisal v celoti glede na onaglašenost njegovih oblik, ampak samo opozarja na ustrezne strani (102-107) v AH. Tam onaglašeno je sledeče: Sva bilá, sta bilá, sta (bil)é, á za dvojino, za množino pa Jmo bilé, Jte bilé, bilá, Jo bilé; debi mi bilá, bilé, bila.

2 Sedaj pa si mi oglejmo, kako je Bohorič v resnici onaglašal.

2.1 Najprej pri črki/glasu $a$. Dolgi naglašeni $a$ je (po našem štetju) zaznamoval v skoraj 100 primerih, in sicer zelo v skladu s svojimi pravili, tj. pri dvozložnicah na zadnjem zlogu, pri enozložnicah (sicer proti svojemu pravilu) le izjemoma: de fno Jtrán, kár, Stal, kuliku vrát. Pri dvozložnicah je naglas zaznamoval zlasti na zadnjem zlogu, npr. Bokál, Zartám, (Dre)vá, Pregnán, domá, tretják itd. Na zadnjem zlogu je seveda naglas zaznamoval tudi pri tri- in večzložnicah: de eták, imenován, ropotàl. Seveda pa tudi na predzadnjem zlogu: Dopádem, Dopálti, Je dotáknem, dèrsháti - dopèrnáfham. Brez potrebe tudi na prvem zlogu izmed treh: kámenje. Tu je torej Bohorič zelo zanesljiv in se praktično v vsem drži svojih pravil glede na mesto naglasa. Celo kolikost je kdaj upoštevana: ropotàl (pri trepetal pa naglasa ni zaznamoval).

2.2 Podajam listo primerov $\mathrm{z}$ onaglašenim $a$; iz nje bi se tudi najlažje dokazalo, da tonemov Bohorič gotovo ni zaznamoval (akut zaznamujem z A, cirkumfleks s C):

\begin{tabular}{|c|c|c|c|}
\hline Blifkánje $\mathrm{C}$ & Ismáknem A & Je ohráne 3. os. mn. A & Serzá $\mathrm{C}$ \\
\hline Bokál C & Iunák A & $o \int m a ́ k \mathrm{~A}$ & Jtál A \\
\hline Zartám C & Kámenje $\mathrm{A}$ & (Per)á C & trepetáti $\mathrm{A}$ \\
\hline zhetèrták $\mathrm{A}$ & Kár C & Piániz C & Je Jhálim A \\
\hline (Dre)vá C & Kaكhèl A na a & pifár $\mathrm{A}$ & Letá C \\
\hline Strán C & Kopám C & Pokopàm C & tretják $\mathrm{A}$ \\
\hline deveták $\mathrm{A}$ & Kovázh A & Poprávim $\mathrm{C}$ & Besháti A \\
\hline Pregnán A & kováti A & pozhutenjé-njá $\mathrm{A}$ & Vbijánje C \\
\hline domá $\mathrm{C}$ & kovál C & Sdrau C & Vál na vodi $\mathrm{C}$ \\
\hline Dopádem A & vajlá $\mathrm{C}$ & Potlázhim C & vajlám-álh $\mathrm{CC}$ \\
\hline Dopálti A & Kroták C & Pregnán A & v'rálèl $A$ \\
\hline dopâdêl C & Strán C & pèrprávim $\mathrm{C}$ & v'sdiháti A \\
\hline dopèrnálham $\mathrm{C}$ & ráunutjákej $\mathrm{CC}$ & Pèrvádim $\mathrm{C}$ & v'sdiháti A \\
\hline fe dotáknem A & Liltár A & Refpáram A & tàr \\
\hline tretják A & Lonzhár A & ropotáti $\mathrm{A}$ & svunaj sidá $\mathrm{C}$ \\
\hline (Dre)vá C & másal C & ropotàl $\mathrm{C}$ & shelàn $\mathrm{C}$ \\
\hline dersháti A & Mehá $\mathrm{C}$ & Stábo $\mathrm{C}$ & s'hajnem A \\
\hline Shtimám $\mathrm{C}$ & Shelésompèrdám AA & Jedmák A & domà $\mathrm{C}$ \\
\hline$(D u h) a ́$ C & vajlá $\mathrm{C}$ & Jladák C & bilá $\mathrm{C}$ \\
\hline Enák C & $o b a ́ \mathrm{C}$ & (Slá)dkiga A & jïmenováni fo $\mathrm{A}$ \\
\hline Mekák C & dopèrnáfhal $\mathrm{A}$ & Se $\int$ mejáti $\mathrm{A}$ & Rimlán $\mathrm{C}$ \\
\hline Serzá C & Oblák C & v'ráfèl A & kuliku je vrát $\mathrm{A}$ \\
\hline hodá $\mathrm{C}$ & Oblált $\mathrm{C}$ & Smejál C & \\
\hline Hèrzháti A & Odrálètk C & Smrád C & \\
\hline Hèrkáti A & Odvsámem A & Se Správim $\mathrm{C}$ & \\
\hline
\end{tabular}


C̆rka à ne zaznamuje le a-jevskega polglasnika, ampak tudi pravi kratki a: kadàr, kasàl, klizàl, masàl, Pintàr, ropotàl, Lambergar/èr, Jta bilá. Tu sta se Bohoriču križala polglasnik in kratki $a$, večinoma naglašen, včasih pa tudi nenaglašen. Zapis dolgega a z à je pač pisarska ali stavska napaka.

Večina á-jev je cirkumfleksna (čez 50 primerov), akutov pa je pod $40 .^{5}$

2.3 Nekatere teh enot imajo po dva naglas nika: krativčni od Krelja naprej v takih primerih zaznamuje polglasnik, ki je sicer lahko različno obarvan. Zgledi za to so: zhetèrták, dopádèl, dopèrnálham, Hèrzháti, Hèrkáti, Odráfèlk, pèrdám, pèrprávim.

2.4 Ko že govorimo o polglasniku, povejmo še, da je večinoma zapisan z è. Zlasti očitno je to pred zvočnikom $l$, kjer ga najdemo 30 -krat, na -àl pa le dvakrat (Mifăl, Trefăl). Ta à je nekak disimilat polglasnika, zlasti med zobnikom in končnim $l$. Zgledi: Fushèl, govurèl, grisèl, Ka/hèl, Kosèl, kradèl, lesèl, mogèl, Modèl, prifhèl, navadèl, nefèl, obèl, Odráfèlk, padèl, pekèl, pèrvèrgèl, perjatèl, pri/hèl, rafêl, Jkubèl, Tempèl, topèlt, vlékèl, vogèl, vráfêl, prifhel, shivèl. V primerih govurèl, navadèl sta è pač iz $i$.

Zgleda pred $r$ sta sapèrl in s'dèrl.

Zgledi z è pred nezvočnikoma: zhès, donès, dèsh, Goltanèz, Hribèz, Konèz, Kratèk, Krivèz, Nòshizhèk, Polèg (v SSKJ: tudi a), Sklèp, Sodèz, Kratèk, Sapopadèk. Po svoje je posebej zanimiva beseda $S m i / h l a u z$, kjer bi pred $z$ pričakovali samoglasnik (è, če ne celo $\grave{a}$ ): torej je tu polglasnik že upadel do nič. Vseh okrativčenih zgledov je za polglasnik $14, \mathrm{v}$ besedah zhes in Sklèp pa sta $e$-ja. V nekaterih primerih je prvotni polglasnik, ko ni naglašen, dal $i$, npr. lóshiz (manjšalnica od log), to pa ob hkratnem Goltanèz, Hribèz, Konèz, Krivèz, Sodèz, pa Gibézhin, fin Jna, Léfim, vshil (toda prifhel). Posebna oblika je tudi Ogèjn (kar na Mostecu daje ógi ógja). É v Gibézhin je pač pomota za gibčen ali zgledovanje po Gibèk.

Pred - $n$ ima Bohorič zapis polglasnika z è: Rasèn, Brumèn, Kamèn, eden -dna, Narasen, Medèn, nepravizhén (pač é po pomoti za è), Obedèn, edèn, pametèn, Potrébèn, Perjasèn -sni, Brumèn, pèrjetèn, Revèn, ritèn $\int k i$, Sìn Jna, Jpodobèn, Srezhèn, Sènz, Stanovitèn, Schlahtèn, trudèn, Turén. (Tudi Turén je spregled za Turèn.) Na podlagi teh dveh primerov nasproti 23 pravilnim s krativcem pač ni mogoče govoriti o mešanju, ampak gre za posamezne spreglede.

Zgledi na àn so: Edàn, Croat. iedán, vredàn, svojovojlàn, Vmétalnoft, vmétèlàn, vredàn, shelàn. Skupaj 8 , od tega brez krativca 2 .

Podobno je pri končaju er, kjer je razmerje 10 pravilnih proti 2 nepravilnima: Bebèr, dobèr, kokèr, Hitèr, kèrbodi (4-krat), ker (= ki), sa ni/hter, Modèr, Neojftèr, Stebèr, supèr - kamér, Zuntér, tj. $14: 2$. (Vse se mi zdi, da imamo na Mostecu v teh primerih er s pravim $e$, npr. véter - nimamo pa seveda koker.)

Namesto èr imamo kar 13-krat àr oz. -àr-: Dobàr, pre,dobàr, kadàr-Gàrba, gàrdu, ná gàrli, obdarshé, Smàrt, fàrdit, najpogosteje za strnjenim soglasnikom (prvi trije nekončni primeri) oz. za temnim ustničnim $b$ (Dobar, dobàr, pre,dòbàr, vendar tudi dobèr), pa za $m$ (Smàrt), za zobnikom pa v primerih kadàr, obdàrshé, Jardit, vendar zmeraj hkrati pred $r$.

\footnotetext{
${ }^{5}$ Treba je povedati, da je Bohorič vendarle ustrezal svojemu pravilu naglaševanja. Že S̆krabec je bil glede tega precej jasen.
} 
2.5 Sredinski e-ji oz. o-ji: Bohorič res ni imel posebnega zaznamovanja za dolgi ozki oz. široki o, ampak je oba pisal enako kakor ozkega, tj. z ostrivcem, le da je bilo dolgih ozkih e-jev neprimerno več kot širokih. Razmerje med $e$ : in $o:$ je 80 proti 6 . široki dolgi $e$ imajo naslednje besede: débel, Nagnjétem, nagnjéfti, Pobérem, (po)méfti, (po)médel, Pométem (če (po)médel vendarle ne zaznamuje ozkega: po zgledu nêsti, nêsem proti nésel). Besede $\mathrm{z}$ ostrivcem na $e$ za dolgi ozki $e$ so pa naslednje (po stolpcih za nekdanji jat, nosni $e$ in etimološki $e$ ):

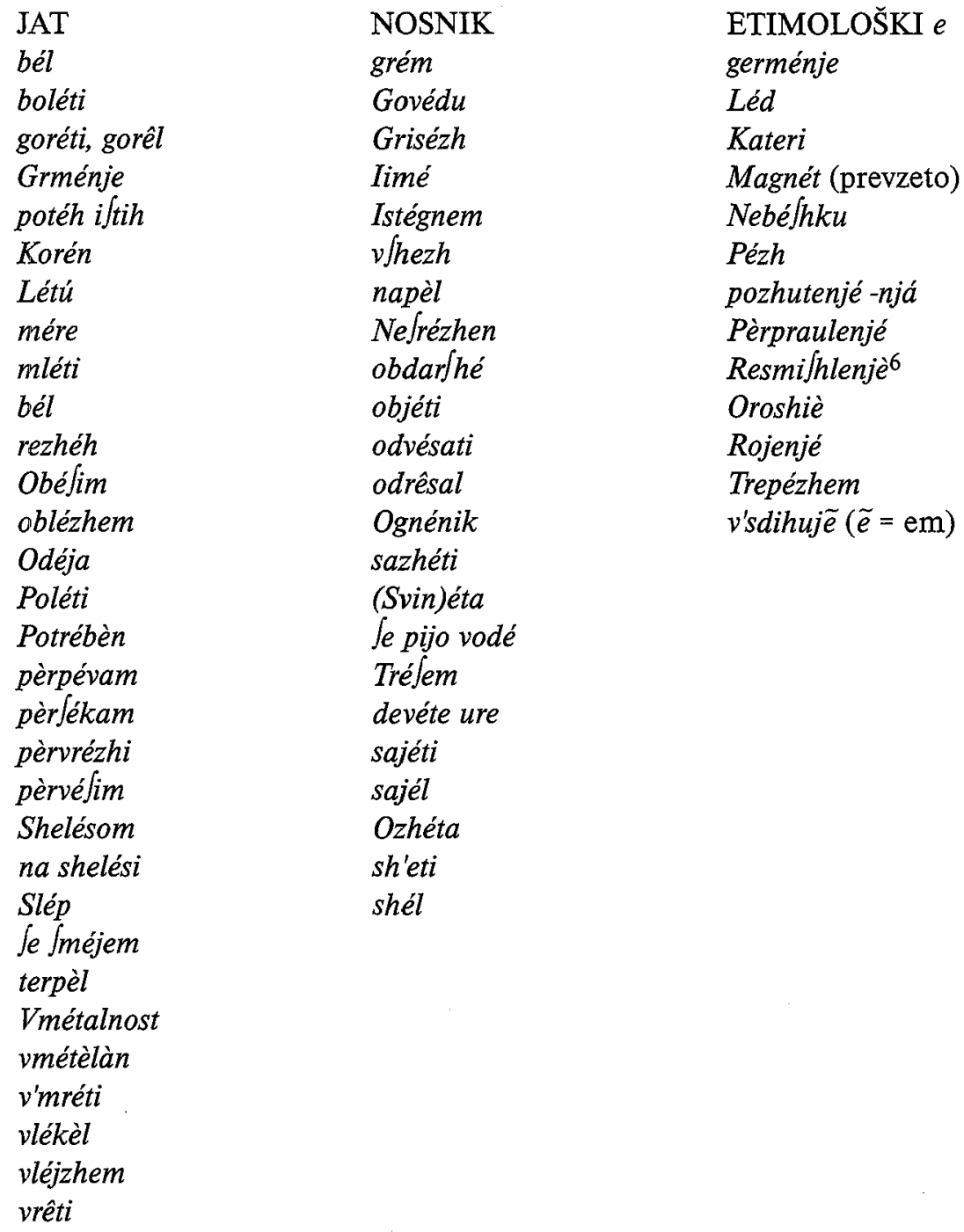

\footnotetext{
${ }^{6} \mathrm{~V}$ takih primerih se je kazala slabost zaznamovanja polglasnika s krativcem, ker se zaradi tega ni dal zaznamovati kratki naglašeni $e$. To deloma velja tudi za $a ̀$ in še za ò (za ò prim. Tòlzhem tòlzhi).
} 
Ne glede na izvor Bohorič vse e-je zaznamuje $\mathrm{z}$ ostrivcem, npr. bél za jat, gré za nosnik, Sheft za etimološki . Izjema je le oblika vleizhem, že opisni deležnik (vlékèl) pa ima samo é. Naglasna mesta so v veliki večini sodobna, posebnosti so le: Lajshéfhi, Ognénik in Létú (zađnje pač s pomotnim ú namesto $u$ ). Posebnosti so še pri glagolnikih; naglašeni so na tri načine; če imajo končaj -enje: Germénje - jemlenjé, pozhutenjé, Rojenjé - Resmi/hlenjè, Pèrpraulenjè, enkrat tudi na -tje: Pitje; podobno pa je naglašeno tudi Oroshiè.

Čudno naglaševanje glagolnikov je opazil že Kolarič in pri tem opozoril na navadnost takega naglaševanja na koncu besede na severovzhodnem slovenskem področju, "kjer je to očitno mogoče" in domače. Oblika pojém v zvezi pomalim pojém je pač pôjem $\mathrm{v}$ okviru iztočnice pèrpévam (z ostrivcem je zaznamovan nenaglašeni $e$, ne polglasnik). En sam primer je, ko je ostrivec na e za široki $e$ : fe sanélem, sanéfti. Ne prav jasni posebnosti sta zapisa Smiét in Svier, prvo za pojem 'zmaj', drugo za 'žival'.

Besede s krativcem na $e$ so naslednje: Oroshiè, pre /hèrn, Pèrpraulenjè, Resmifhlen$j e ̀$, Jklèp, terpèl, vrèm, vrèl, shivèl, s strešico pa vrêti. Večkrat pa mu krativec zaznamuje polglasnik: Potrébèn, pèrsékan, vlékèl, umétèlàn. V drugih naštetih besedah krativec verjetno res pomeni kratki naglašeni $e$. Obliko umétèlàn $\mathrm{z} a ̀$ za polglasnik si razlagam kot disimilacijo $e$ v a (med dvema zobnima zvočnikoma).

$\breve{C r k a} o$ z ostrivcem je sorazmerno redka, samo črka $u$ je še redkejša. Gradivo je naslednje: Za ozki ó je le 14 primerov. To so odrazi nosnega $o$ (5 primerov: Berózh, nad glavó, lóshiz, pèrtóshim, Reslózhim), drugi pa so etimološki, namreč: pójeni, Isbódem, Obnórim, Pokórim, neprimóre, v'vóla, v'vóli. Umično naglašena na prvotni kračini sta isbódem in vóla, vóli, danes v knjižnem jeziku široka in dolga. Tòlzhem, tolkèl in tòlzhi so iz zložnega $l$, prvotna polglasniškost kračine je zaznamovana z ò (na Gorenjskem, Nemški Rovt: tléč, tlčèm). Nepričakovani naglasni mesti (Obnórim, Pokórim) imam potrjeno kot še sedaj živo krškovaškem govoru, kjer sem slišal in se prepričal o tem ob obliki govórim. Nekaj prvotno cirkumfleksnih o-jev je prešlo v $u$ : Túp (prim. v SSKJ variantno obliko za srednji spol ed. topộ). Podobno še /kús in leúni -a leunu, leunod, letú). Taka u-ja sta še Blagú (dvakrat) in Perú.

2.6 Prvotni $u$ je ohranjen (s'mersújem). V primeru s'mersúvati je pa $u$ iz o (na Mostecu zmrzuváti, ne zmrzüvati).

3 Jakob Rigler (Začetki slovenskega knjižnega jezika, 1968, 201-202) pripisuje Bohoriču tudi Register v Dalmatinovi Bibliji 1584, tj. 13 neostranjenih strani na koncu Biblije s 775 besedami: "Več stvari je, ki odločno kažejo na Bohoričevo avtorstvo. Tako npr. v slovnici kot v Registru ni razlike med pogostnostjo zapisov z é glede na to, ali gre za $e$ ali ne, ampak označuje é le dolgi $e . "$

Če podrobneje gledamo na $e$-je, ugotovimo, da je velika večina (47) takih e-jev v Registru izjatovska, komaj en é je izetimološki (obéden), dva sta iznosniška (vodé), pridno pa Bohorič zaznamuje tudi polglasnike. Takole: 


\begin{tabular}{|c|c|c|c|}
\hline $\begin{array}{l}\text { e } \\
\text { notèr }\end{array}$ & poshèrle & $\begin{array}{l}\text { a } \\
\text { danas }\end{array}$ & $\begin{array}{l}\text { o } \\
\text { kakòr }\end{array}$ \\
\hline nikoger & nèrve & rekàl & kakòr \\
\hline tèrto & poshèrle & gàrde & kakòr \\
\hline pèrvi & poshèrle & màdli & kakòr \\
\hline pèr & poshèrle & gàrde & kakòr \\
\hline poshèrle & modèr & gàrde & kakòr \\
\hline poshèrli & pokorèn & gàrde & kakòr \\
\hline refèrdil & notèr & rekàl & \\
\hline pèr nas & pèrviga & rekàl & \\
\hline notèr & pèrhajali & je Jhàl & \\
\hline nikogèr & tèrpela & rekàl & \\
\hline pèr meni & odpèrl & je Jhàl & \\
\hline pèr kraju & pèrhajale & $\begin{array}{l}\text { Jhàl } \\
\text { prilhàl }\end{array}$ & \\
\hline
\end{tabular}

Razen za jat in polglasnik (tega drugega piše poleg z è (26) še z à (14) in ò (7), vendar zadnje le v besedi kakòr, iz česar lahko vidimo, zakaj je Škrabec tak trdo vztrajal pri pisavi kaker.

4 V nasprotju s pisanjem naglasov v Registru je Dalmatin v Bibliji zelo strogo sleđil Krelju, tako da mu je è zaznamoval polglasnik, é pa jat. Le pri večzložnicah zaznamuje neobičajno naglasno mesto z á: me ispelá, ena Jajná, Sajnála, Je je Jajnála, Pháraonu. Seveda pa Dalmatin na nakazani način ni zaznamoval vseh primerov. Spodrsljaj je pač sapóvej (morda namesto zapové), ko pa je jat zapisal z ej, je ostrivec postavil na predhodni zlog.

Dalmatin sam je v svojem besedilu Biblije (pregledal sem list 26 XL. CAP. desno in list 27 levo in desno) z ostrivcem zaznamoval izjatovski $e$ kar 45-krat, npr. pregréfhila, téh, imélo, povéjte, povédal, néfim, béle, jédle, obéfil itd. v 45 primerih, s krativcem pa je pisal le dva taka primera, tj. svèdla in imèl. Naglasno mesto v pregréfhila je pač le analogija po pravilnem pregréśil, primera s krativcem pa sploh zaznamujeta izjatovski kračini.

Polglasnik je Dalmatin zaznamoval s krativcem, najsi bo na črki $e$ (npr. notèr, nikogèr, tèrto, pèrvi, pèrgudilu, pèr eni vodi, Jo poshèrle itn.) ali na $a$ (npr. danas, gàrde, màdli, rekàl, fhàl, prifhàl), z $o$ pa pisal samo, ko gre za besedo kakòr.

Drugi samoglasniki so v Bibliji le redko onaglašeni: v'ròke (umično naglašeni analogni široki etimološki $o$, kolikor ne gre celo za ozki $o$ po pomiku, Jajné, poménjo (iznosna e), Jajná, Jajnála, Je je Jajnálu (prvotni a), obédan (široki dolgi e, naglašen umično). $V$ teh primerih je Dalmatin zaznamoval naglasno mesto, ne dolgih jatov.

$\mathrm{S}$ povedanim je potrjena Riglerjeva misel, da je "REGISTER Nekatérih befed,

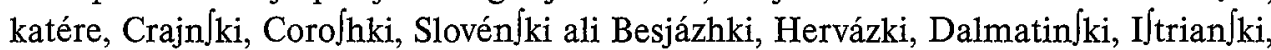
ali Cra $\int h k i$, Je drugázhi govoré", res sestavil Bohorič, saj je ostrivec tudi v naslovu 
Registra enako stavil na izjatni $e$ (beséd, Slovén/ki) kakor na etimološki ali iznosni $e$ (Nekatéri, Katére, govoré), kakor tudi na a (Besjázhki, Hervázki).

Iz te obravnave se tudi vidi, da Kolaričeve negativne trditve glede rabe naglasnih znamenj pri Bohoriču v glavnem niso objektivne.

\section{Zusammenfassung \\ DIE BETONUNGSZEICHENSETZUNG IN BOHORIČ'S ARCTICAE HORULAE 1584}

Die Betonungszeichen $/ \%$ und $/ /$ gebrauchte im Slowenischen als erster S. Krelj, und zwar den Akut (l'accent aigu) als den Marker für das lange betonte Jat, und den Brevis (l'accent brève) als den Marker des Schwa (bzw. der quantitativ reduzierten Vokale überhaupt). A. Bohorič hat diesen zwei Zeichen die Funktion der Bezeichnung der Länge bzw. đer Kürze zugeschrieben. Den Akut sollte man nach ihm auf den nicht penultimen Silben verzeichnen, den Brevis aber an beliebiger Silbe, die kurz und (besonders zugleich) betont ist.

Darüber haben schon vor uns Stanislav Škrabec (1913), Jakob Rigler (1968) und Rudolf Kolarič (1971) geschrieben. Der Letzte war (ungerecht) der Meinung, dass die Bohorič'sche Realisierung seiner eigenen diesbezüglichen Regeln sehr unvollkommen wenn nicht systemlos wäre. Unser Aufsatz zeigt unter der Berücksichtigung des gesamten betreffenden Materials der Akzentsetzung in den Arcticae Horulae, dass Bohorič sich (mit einigen Ausnahmen, die auch dem Setzer zum Teil zuzuschreiben sind) sehr wohl an seine Regeln gehalten hat, wie es schon Škrabec bezüglich der Setzung des Brevis gezeigt hatte. 